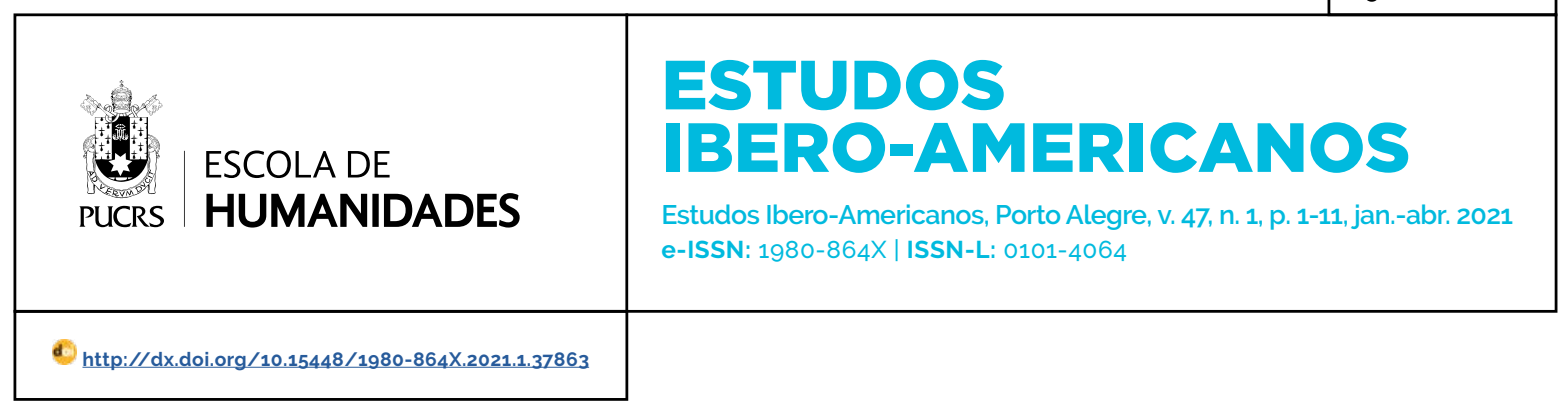

DOSSIÊ: HISTÓRIA DAS MULHERES, DAS RELAÇÕES DE GÊNERO E DAS SEXUALIDADES DISSIDENTES VOL. 47, N. 1.

\title{
Algunos reflexiones sobre género y memoria en las narrativas sobre los años setenta en Argentina
}

\author{
Algumas reflexões sobre gênero e memória em narrativas sobre os anos 1970 na Argentina \\ Some reflections on gender and memory in the narratives of the 1970 in Argentina
}

\author{
Ana Laura Noguera ${ }^{1}$ \\ orcid.org/0000-0001-8737-4467 \\ analauranoguera@gmail.com
}

Recebido em: 28/04/2020

Aprovado em: 11/01/2021

Publicado em: 30/04 2021
Resumen: Hace varios años que el campo de la denominada Historia Reciente ha cobrado especial legitimidad, al menos dentro de la historiografía argentina. Como han demostrado numerosas investigaciones, en la Argentina de los años setenta las mujeres fueron activas participantes de diversas organizaciones sociales y político-militares. Sin embargo, tras la recuperación democrática de los años ochenta y buena parte de los noventa, las narraciones que dieran cuenta de dicha participación fueron invisibilizadas.

Desde estas coordenadas, en este artículo nos proponemos hacer algunas reflexiones teórico-metodológicas de los vínculos entre género y memoria en la historia reciente. Señalaremos, por un lado, los aportes que la historia de las mujeres con perspectiva de género le confirió a la historiografia tradicional. Por otro lado, reflexionaremos sobre los vínculos entre género y memoria en las narraciones de mujeres y varones militantes politicos. Finalmente, realizaremos un breve recorrido por las producciones que desde el campo de la historia reciente han analizado los sesenta y setenta en nuestro país.

Palabras clave: Género. Historia Reciente. Historia Oral. Memorias

Resumo: Há vários anos, o campo da denominada História Recente ganhou especial legitimidade, pelo menos dentro da historiografia argentina. Como demonstraram numerosas pesquisas, na Argentina, na década de 1970, as mulheres participavam ativamente de várias organizações sociais e político-militares. No entanto, após a recuperação democrática dos anos 80 e boa parte dos anos 90 , as narrativas que representavam essa participação foram tornadas invisiveis. A partir dessas coordenadas, neste artigo, propomos fazer algumas reflexões teórico-metodológicas sobre os vínculos entre gênero e memória na história recente. Apontaremos, por um lado, as contribuições que a história das mulheres com perspectiva de gênero deu à historiografia tradicional. Por outro lado, refletiremos sobre os vínculos entre gênero e memória nas narrativas de ativistas políticos de mulheres e homens. Por fim, faremos um breve tour pelas produções que, do campo da história recente, foram analisadas nos anos sessenta e setenta em nosso país. Palavras-chave: Gênero. História recente. História oral. Memórias

Abstract: For several years the field of so-called Recent History has gained special legitimacy, at least within Argentine historiography. As numerous investigations have shown, in Argentina in the 1970s, women were active participants in various social and political-military organizations. However, after the democratic recovery of the eighties and a good part of the nineties, the narratives that gave an account of such participation were made invisible.

From these coordinates, in this article we propose to make some theoretical-methodological reflections on the links between gender and memory in recent history. We will point out, on the one hand, the contributions that the history of women with a gender perspective conferred on traditional historiography. On the other hand, we will reflect on the links between gender and memory in the narratives of women and men political activists. Finally, we will make a brief tour
Artigo está licenciado sob forma de uma licença Creative Commons Atribuição 4.0 Internacional. 
of the productions that from the field of recent history have analyzed the sixties and seventies in our country. Keywords: Genre. Recent History. Oral History. Memories

Como todos los historiadores sabemos, el pasado es una gran tiniebla llena de resonancias.

Desde ella nos llegan algunas voces; pero lo que nos dice está imbuido de la oscuridad de la matriz de la cual salen.

$Y$, por mucho que lo intentemos, no siempre logramos descifrarlas e iluminarlas con la luz, más clara, de nuestro propio tiempo.

Margaret Atwood, El cuento de la criada, 1985

\section{Introducción}

Hace varios años que el campo de la denominada Historia Reciente ha cobrado especial legitimidad, al menos dentro de la historiografía argentina. Su emergencia estuvo vinculada -como en otras partes del mundo- a una diversidad de cuestiones sociales. Por un lado, tuvo gran incidencia el peso de procesos pasados-presentes violentos y traumáticos. En segundo lugar, respondió a demandas sociales de grupos subalternos, en un proceso de visibilización de "otras historias". Y, finalmente, se relacionó también con la crisis de las ciencias sociales, en general y de la historia en particular, durante la década del ochenta.

En Argentina, una vez concluida la dictadura cívico-militar (1976-1983), comenzaron a producir los primeros escritos académicos/testimoniales referidos a ese pasado inmediato. El apremio por abordar el carácter violento y traumático de la experiencia dictatorial, construyó inicialmente una agenda de investigación centrada en esta temática, convirtiéndose asi en su elemento constitutivo. Las pesquisas giraron en torno a las violaciones hacia los Derechos Humanos, los procesos de conflictividad social-obrera-estudiantil, la lucha armada y el despliegue de los aparatos represivos (Franco y Levín, 2007).

Se produjo, entonces, un estallido del campo de "las memorias" sobre los años setenta, muchas de ellas con un común denominador: la crítica a la violencia "de ambos lados" -los "dos demonios"- y los intentos de explicación de la derrota del proyecto revolucionario, enmarcadas en un contexto histórico y de escritura sobre el pasado reciente que Roberto Pittaluga y Alejandra Oberti (2006) han denominado de "estrategia democrática".

Como han demostrado numerosas investigaciones, en la Argentina de los años setenta las mujeres fueron activas participantes de diversas organizaciones sociales y político-militares. En ellas, asumieron todo tipo de actividades que iban desde intervenir en asambleas, conflictos gremiales y estudiantiles hasta impulsar "Frentes de Mujeres", desarrollar el trabajo barrial o tomar las armas.

Sin embargo, tras la recuperación democrática de los años ochenta y buena parte de los noventa, las narraciones que dieran cuenta de dicha participación fueron invisibilizadas. Esto respondió, en cierta medida, a un posicionamiento marginal de la historiografía, quién se mantuvo alejada de estas discusiones, más aún en aquellas que se proponian problematizar las experiencias de sociabilidad entre los sexos y las representaciones del mundo en relación al género y a la política en este período (Cfr. Viano, 2011; Pasquali, 2008).

Desde estas coordenadas, en este artículo nos proponemos hacer algunas reflexiones teórico-metodológicas de los vínculos entre género y memoria en la historia reciente, elaboradas a partir de nuestro propio trabajo de investigación, que indaga sobre la participación de las mujeres en organizaciones político-militares de los años setenta en Argentina. Señalaremos, por un lado, los aportes que la historia de las mujeres con perspectiva de género le confirió a la historiografía tradicional al proponer una lectura que discute, entre otras cosas, que no debe soslayarse el carácter sexuado de las experiencias de las y los sujetos. Por otro lado, abordaremos el uso de la historia oral como una metodología útil a la hora de analizar procesos socio-políticos recientes, para detenernos particularmente en la reflexión sobre los vínculos entre género y memoria en las narraciones de mujeres y varones militantes políticos. Finalmente, realizaremos un breve recorrido por las producciones que desde el campo de la historia reciente han analizado los sesenta y setenta en nuestro país. 


\section{Cartografías disciplinares I: Historia y Género}

En un texto clásico dedicado a la escritura de la historia, Michel De Certeau se preguntaba, "¿Qué fabrica el historiador cuando hace historia'? ¿En qué trabaja? ¿Qué produce?" (De Certeau, 1993[1978]: 67)². Estás preguntas han recorrido gran parte de los debates dentro del campo disciplinar en las distintas épocas, y han sido particularmente intensos en momentos de crisis epistemológica, como el acontecido a fines de los años ochenta con la caída del muro de Berlin y del "socialismo real"3. Del profuso debate producto de este (re)visitar la historia y la tarea del historiador nos interesa explicitar algunos nudos problemáticos que estructuran nuestras indagaciones. En primer lugar, creemos necesario concebir la historia como un entramado dialéctico entre un hacer, una práctica cientifica pero también politica, un lugar social, el del historiador que indaga el pasado desde un presente inserto y en diálogo/disputa con las construcciones sociales de su tiempo, y una escritura, que combina estructuras narrativas literarias con las "reglas" propias del método historiográfico (De Certeau, 1993[1978]; Chartier, 1996).

Por otro lado, la historia en tanto conocimiento situado (Haraway, 1991), contingente y variable, marcado temporal, espacial y corporalmente, contribuye, en palabras de Joan Scott:

[...] De forma crucial, como participante en la producción del conocimiento sobre la diferencia sexual. Parto de que las representaciones de la historia del pasado ayudan a construir el género en el presente [...] En este sentido, la historia opera como un tipo particular de institución cultural que aprueba y anuncia las construcciones de género (SCOTT, 2011[1999]: 20-29).

Estas premisas señaladas por Scott estuvieron ciertamente presentes en los debates sobre los objetos/sujetos "legítimos" de la historia4; así, en sintonía con la renovación de la Historia Social y Cultural y por la influencia del pensamiento feminista, la Historia de las Mujeres cobró, hacia fines de los años ochenta, creciente vigor en los distintos espacios académicos. En términos generales, esta perspectiva tuvo como objetivo central rescatar a las mujeres como objeto/sujeto de la historia, otorgándoles visibilización y entidad a quienes hasta entonces habian sido ocluidas por las perspectivas androcéntricas de la disciplina. La renovación implicó una apertura no sólo a nuevas temáticas -como la familia, la sexualidad y la maternidad- sino también dio paso a nuevos cuestionamientos e interrogantes. De esta manera, las distintas épocas fueron releidas en función de este "novedoso" problema de investigación, a lo que se sumó el uso de fuentes hasta entonces ignoradas (Cfr. Bock, 1991; Scott, 2011[1999]).

Sin embargo, lo que en un primer momento resultó provocador para la disciplina gracias a su potencial crítico, encontró sus limitaciones al reproducir aquello que habia pretendido cuestionar: una historia descriptiva que, al nominarla como "la mujer" en la historia, reproducia el esencialismo del sujeto, a lo que se sumaba la ahistoricidad de algunos conceptos que, elaborados desde la actualidad, no coincidían con las formas en que fueron concebidos en épocas anteriores (Cfr. Acha y Halperin, 2000).

El concepto de género 5 , al deconstruir las nociones biologistas/esencialistas/universalistas (Bonder, 1998) que sostienen que la diferencia entre los sexos es producto de determinaciones naturales, propone repensarlas como una interacción social dinámica, una relación social (De Lauretis, 1996[1989]), en permanente transformación, siendo fundamental para el análisis histórico la consideración de los diversos espacios, las distintas temporalidades, contextualmente inmersos

\footnotetext{
2 Retomo aquí las consideraciones expresadas por el autor para concebir la historia: "(...) en el sentido de historiografía, es decir, que entiendo por historia una práctica (una disciplina), su resultado (un discurso) y la relación entre ellos" (De Certeau, 1993[1978]:67).

3 El debate fue (y continúa siendo) motivo de reflexión dentro de la disciplina. Para una referencia ver Chartier (1996); Traverso (2012).

4 En este sentido, Georges Duby y Michele Perrot señalaban, en el prólogo a la hoy clásica obra colectiva dedicada a la Historia de las Mujeres, que las narraciones sobre la Historia que no den cuenta en su entramado de la experiencia de las mujeres -o la oculten- no pueden pretender, si es un deseo anhelado, intentar reconstruir una historia total (Duby y Perrot, 1993).

5 El género(s) como categoría analítica es objeto de numerosos debates y producciones que lo han abordado desde múltiples campos teóricos -feminismos, estudios queer, estudios de masculinidad- tanto dentro del campo académico como del "activismo". No es el objetivo del presente trabajo profundizar sobre este profuso debate; para algunos textos de referencia ver Scott (2011[1999]); Ramos Escandón (1992); Butler (2001); Benhabib y Cornell (1990); De Lauretis (1996[1989]), Haraway (1991)
} 
en la raza, la clase, la religión, entre otras diferenciaciones (Okin, 1996[1994]). Es decir, nos invita a analizar cómo el sistema sexo-género ha creado una compleja red de dispositivos discursivos, de prácticas e institucionalidades, donde los sujetos se en-generan "en y a través de estos dispositivos, posiciones y sentidos singulares" (Bonder, 1998) 6 .

En este sentido es preciso concebir el género como el resultado de la producción de normas culturales sobre el comportamiento de los sujetos mediado por la compleja interacción de cuatro aspectos o niveles que Joan Scott definiera en su ya clásico artículo "El género, una categoría útil para el análisis histórico": primero, símbolos culturalmente disponibles que evocan representaciones múltiples y a menudo contradictorias. Segundo, conceptos normativos (doctrinas religiosas, educativas, científicas, legales y politicas) que manifiestan las interpretaciones de los símbolos y que otorgan un significado especifico de varón y mujer, femenino y masculino. El tercer aspecto hace referencias a la dimensión política e institucional de lo anterior (sistema de parentesco, mercado de trabajo, economía, política). El cuarto aspecto es la identidad subjetiva, es decir, la construcción de identidades genéricas (Scott, 2011[1999]).

En relación a esto, la "construcción histórica-social de los géneros" supuso también, en las sociedades patriarcales occidentales, la división de la organización social en dos espacios: uno esencialmente público/masculino y uno esencialmente privado/femenino, donde varones y mujeres ocupan espacios diferenciales y, por tanto, generizados, promoviendo prácticas y representacion propias de cada uno de ellos (Fernández, 1993). En palabras de Seyla Benhabib y Drucilla Cornell:

[...] La distinción entre esfera pública que está abierta a todos por igual, y la esfera privada intima que se basa exclusivamente en el amor y el afecto, y el contraste entre el bien público y común y otros intereses conflictivos, privados y parciales [...] ha justificado la exclusión de las mujeres, los que no son varones blancos y adultos no apropiados (BENHABIB Y CORNELL, 1987 [1990]: 9-28).
El concepto de género posibilitó la reflexión crítica respecto de las implicancias de esta división jerarquizada del espacio social, donde la oposición de los binomios público/privado lleva en su seno explicitamente otros pares de oposiciones: razón/ sentimiento, poder/afecto, producción/consumo. Desde nuestra perspectiva, es importante destacar la conjunción de lo personal y lo político, tal como se ha expresado en el lema feminista enunciado por Kate Millet a fines de los sesenta, "lo personal es político", es decir, en la doble vertiente de "politización de lo personal y personalización de lo político" (Millet, 1969 [1975])7.

En suma, y siguiendo a Dora Barrancos (2007), el análisis debe enfocarse en los condicionantes forjados socio-culturalmente -históricamente situados-, cuestionar las representaciones, las ideologías, las mentalidades, que definen lo masculino y lo femenino y las actividades y expectativas de comportamiento apropiadas para cada uno. En palabras de Débora D’Antonio: "Es necesario explorar la identidad de género femenina como constitutiva de una agencia política en relación, contraste y comparación con la agencia política masculina" (D'Antonio, 2010:44). Creemos que la recuperación de la agencia, de la dimensión "política" del género -y, por tanto, su vinculación con el ejercicio del poder- es fundamental al momento de historiar las experiencias subjetivas de mujeres y varones; recuperar sus acciones y cómo trasformaron (o no) las performances de género, complejiza de manera creciente los análisis enfocados sólo en la subordinación y opresión sufrida por las mujeres.

\section{Cartografías disciplinares II: Memoria, Fuentes Orales y Género}

Es necesario señalar aqui un eje central para quienes se abocan a la historia del tiempo presente. Como ha señalado Enzo Traverso, desde los años ochenta, las nociones de sociedad y clases sociales fueron progresivamente relegadas a

\footnotetext{
6 En palabras de Teresa De Lauretis: “Un sujeto constituido en el género, seguramente, no sólo por la diferencia sexual sino más bien a través de representaciones lingüísticas y culturales, un sujeto en-gendrado también en la experiencia de relaciones raciales y de clase, además de sexuales; un sujeto, en consecuencia, no unificado sino múltiple y no tanto dividido como contradictorio" (De Lauretis (1996[1989]: 8) 7 Ver también Pateman (1996).
} 
un segundo plano situándose en el centro de la escena los estudios sobre memoria e identidad, convertidos ahora en objetos primordiales de investigación histórica (Traverso, 2012).

En este camino, la utilización del testimonio como herramienta para la reconstrucción del pasado reciente ha crecido exponencialmente en los últimos años. La carencia de fuentes escritas, la dispersión de los archivos, el dificultoso acceso a la documentación privada (cartas, fotos) y la casi inaccesibilidad a una parte del acervo documental de la justicia -ya que contiene "información sensible"- son algunos de los obstáculos a los que se enfrentan las investigaciones basadas en estas temáticas. De esta manera, la posibilidad de recuperar la experiencia de los "testigos" ha llevado a la mayoria de los investigadores a recurrir a la memoria y la oralidad como fuentes centrales en sus trabajos.

Creadas conjuntamente entre entrevistador y entrevistado, las fuentes orales, conceptualizadas por Ronald Grele (1991) como narraciones conversacionales, engloban un conjunto interrelacionado de estructuras literarias, sociales e ideológicas. El carácter de performance -en tanto dramatización- de las entrevistas, convoca a analizarlas no sólo por las imágenes que evocan, sino también por la forma en que se realizan las mismas y por las circunstancias y el contexto en que se ven inmersas (Vich, y Zavala, 2004). Los discursos orales, entonces, constituyen a la vez narración histórica y conversación de cada uno de los participantes respecto de sus tradiciones culturales, sociales, políticas a las cuales -y a través de las cuales- hablan. La relación se teje, de esta forma, entre el testimoniante, su propia conciencia histórica y un público más amplio al que está dirigido el relato (Grele, 1991).

En palabras de Alessandro Portelli, "Las fuentes orales nos dicen no sólo lo que hizo la gente sino lo que deseaba hacer, lo que creian estar haciendo y lo que ahora piensan que hicieron" (Portelli, 1991: 42). Ellas expresan la subjetividad del testimoniante en un proceso de reconstrucción del pasado, realizado en estrecha relación con necesidades del presente y en perspectiva de futuro.

Por otra parte, numerosos autores, muchos de los cuales utilizan la historia oral como metodología, han insistido en la necesidad de diferenciar la historia de la memoria, más aún si la misma es objeto de indagación histórica. Paul Ricouer (2008 [2000]) ha señalado el aspecto matricial de la memoria en relación a la historia, aunque esta última, al constituirse como ciencia, (re)construyó el discurso en relación al pasado sobre la base de reglas científicas críticas.

La memoria está constituida por un conjunto de recuerdos individuales y representaciones sociales sobre el pasado. En tanto no está fijada, ya que es reelaborada desde el presente, es contingente y está sujeta a las alteraciones producto del paso del tiempo y la acumulación de experiencias adquiridas. Las memorias individuales -subjetivas, únicas y singulares- siempre se entrecruzan e interrelacionan con memorias colectivas, los marcos sociales que proyectan las representaciones sociales generales, asi como también valores y códigos culturales compartidos, más o menos estables, a modo de cultura heredada (Halbwachs, 2005). En palabras de Jerome Bruner "Las narraciones que nos contamos a nosotros mismos, que construyen y reconstruyen nuestro Yo, abrevan en la cultura en que vivimos" (Bruner, 2003:124).

La memoria nos confiere identidad y estructura nuestra subjetividad ${ }^{8}$. Qué recordar, qué olvidar, qué silenciar y cómo hacerlo, instituye y reconstruye identidades, hilvana o borra secuencias y encubre o alumbra ciertos sucesos, actores o momentos. De lo que se recuerda y olvida se desprenden pertenencias, un "nosotros", en un ejercicio político activo de elaboración y construcción simbólica sobre el pasado, siempre en relación al presente desde el cual se narra y donde se enhebran procesos subjetivos complejos, históricamente situados, que involucran no sólo la clase, sino también el género, la generación y la raza, por mencionar algunas de las variables a considerar.

Es preciso decir aquí que los estudios historio-

8 Siguiendo a Pollak, la identidad "es un componente extremadamente importante del sentimiento de continuidad y de coherencia de una persona o de un grupo en su reconstrucción de si" (Pollak, 2006: 38). 
gráficos sobre las mujeres y los géneros tuvieron desde sus origenes una estrecha vinculación con la historia oral, ya que el uso de las fuentes orales posibilitó no sólo darle visibilidad a la voces de mujeres y varones de sectores subalternos sino también ampliaron el campo de indagación hacia otras temáticas como la vida cotidiana, la subjetividad, la identidad y la experiencia. Como ha señalado Paul Thompson (2004), la utilización de las historias de vida han permitido acceder a cuatro ejes temáticos que consideramos centrales para los estudios de memoria(s) y género(s): las voces ocultas, que rescata las experiencias de aquellos alejados del poder y marginados de la historia -las mujeres y otros sujetos subalternizados-; las esferas escondidas -las relaciones familiares, la infancia, la vejez-; los mitos y tradiciones orales y las conexiones entre vidas.

Quisiéramos detenernos aqui en algunas reflexiones sobre género y memoria elaboradas a partir de entrevistar mujeres y varones militantes políticos. Como hemos mencionado existe una estrecha vinculación entre la historia oral y los estudios históricos sobre mujeres y géneros, ya que la utilización de testimonios permite reconstruir no sólo acontecimientos no registrados en los documentos sino también hacer una relectura de ellos a partir del contraste, dialogo y complementariedad entre los registros orales y escritos. La utilización de la historia oral permite además, y fundamentalmente, problematizar la incorporación de sujetos invisivilizados en el relato histórico hegemónico. ¿Cómo reconstruir las experiencias de las militantes políticas si nos enfrentábamos con una doble invisibilización, en tanto mujeres y en tanto activistas de organizaciones clandestinas, y por tanto, ilegales durante la mayor parte de su existencia? Partimos de la certeza que indagar desde una perspectiva sexo-genérica los años setenta y particularmente las prácticas políticas (y la construcción del poder) de las mujeres en esa época suponía analizar las implicancias relacionales del género, en tanto estructurante de las relaciones sociales y cómo las mismas se habian desplegado en los modos en que varones y mujeres se vincularon hacia el interior de los espacios de militancia política.
Ahora bien, si retomamos aquí los elementos señalados por Elizabeth Jelin (2002) para pensar los procesos de construcción de memoria: por el sujeto que recuerda, por el objeto recordado, por las formas en las que se recuerda y por el tiempo en el que se sitúa la operación, el concepto de género no puede ser soslayado en la medida en que las narrativas construidas en torno al pasado son realizadas desde el propio género, lo que aporta a los relatos una posición socializada de cómo deberíamos comportarnos y ello se vierte en los testimonios (Stanley, 2002). Un análisis del modo en que varones y mujeres narran sus historias de vida destaca el uso diferencial de pronombres personales: mientras que los varones utilizan el "yo" de manera activa, las mujeres utilizan de manera más usual el "nosotros" -familiar/ domético o familiar/político- o el neutro "uno" (Thompson, 2004; Pollak, 2006).

Encontrar aquello que atraviesa y comunica las experiencias entre las y los militantes de organizaciones político-militares de los años setenta es una tarea compleja: las narraciones son variadas, vinculadas en buena parte a los distintos espacios que integraba cada una de ellas/ellos, a los sucesos que les tocó vivir, como así también a aspectos de la vida personal. Sin embargo, se pueden encontrar en los relatos elementos comunes, memoria(s) colectiva(s) compartidas.

Siguiendo a Andrea Andújar (2008), sostenemos que el vínculo entre memoria y género es estructurante y destacamos los elementos señalados por la autora. En primer lugar, la memoria está construida desde y en torno a las diferencias socio-culturales de la diferencia sexual, que incluyen concepciones simbólicas, normativas e identitarias y determina ámbitos de acción social particular para cada uno. Elizabeth Jelin ha señalado que la reproducción de la socializacion de género vertida en los relatos, genera que las mujeres tiendan a expresar más los sentimientos y que los mismos estén estructurados en base a los acontecimientos ligados a la familia y la reproducción, mientras que los de los varones suelen ser más racionales y políticos (Jelin, 2002).

Sin embargo, en los testimonios de mujeres y varones, miembros de organizaciones revolu- 
cionarias, se entrecruzan y tensionan las consideraciones antes señaladas con los elementos propios de la experiencia setentista. Más allá de las ideologías particulares de cada organización, la militancia se convirtió en una forma de vida, otorgando significación a muchos aspectos de la vida de aquellos que participaron de la misma provocando una difusa frontera entre el proyecto personal y el proyecto colectivo revolucionario. Fueron mujeres con una participación pública/ politica significativa, expuestas-al igual que los varones- a los devenires de la clandestinidad, persecución, cárcel o exilio. La intensidad que tuvo en sus vidas la militancia estructura sus narraciones y adquiere una centralidad significativa en todo el relato. Además, la misma construcción política-ideológica que las/los contenía -que circunscribía la discusión a los ejes de la contradicción principal imperialismo/pueblo, burguesía/proletariado- provoca que tanto varones como mujeres consideren irrelevante (expresado muchas veces con enojo o con sorpresa) otros temáticas propuestas por los investigadores, tales como las relaciones genéricas, la vida cotidiana, los espacios de ocio de la juventud, entre otros.

En segundo lugar, la memoria es relacional "en tanto se construye a partir de la interacción de los sujetos cotidianamente" (Andújar, 2008:21); aunque no exenta de conflictos en tanto encierra posiciones asimétricas de acceso al poder, valoraciones diferenciales de lo actuado en cada espacio social y (auto)reconocimiento o no de lo realizado en una época determinada. En este sentido, el carácter débil (Traverso, 2007) de la memoria de las mujeres, en relación a la de los varones, ha reproducido las desigualdades entre los sexos en los análisis históricos sobre el período, en la medida en que las propias mujeres consideran que sus experiencias no son interesantes de ser contadas, y, por tanto, escuchadas. Laura Pasquali (2008) ha señalado que dicha subestimación -expresada en los términos "no sé si te va a servir"- respecto de la transmisión de esas experiencias responde no sólo a una cuestión genérica sino que también se relaciona con el posicionamiento de las mujeres dentro de las organizaciones, generalmente en las bases o en los niveles medios de las mismas.

Particularmente en relación a los testimonios de las mujeres que participaron de la lucha armada, algunas autoras han señalado que uno de los temas tabú -que genera silencios y omisiones- es el de mujeres y armas (como expresión del ejercicio de la violencia política) ${ }^{9}$. En nuestra investigación, los testimonios de mujeres que pertenecieron en algún momento al frente militar no demostraron mayor conflictividad respecto al tema del uso de las armas, ni dejaron entrever que se trató, en esa época, de una decisión difícil. No habría conflicto en la medida en que para ellas el uso de las armas, en tanto herramienta para y no como un fin en si mismo, fue producto de un momento particular enmarcado en un contexto histórico de lucha global.

El último elemento señalado por Andújar (2008) es que la memoria está socio-históricamente situada, es decir, que los sujetos no sólo modifican sus concepciones sobre feminidad y masculinidad a través del tiempo sino que también se modifican en función de sus posicionamientos de clase, étnicas o intragénero.

La identificación como compañero/compañera, términos que aludian a una construcción igualitaria entre los sexos a la hora de emprender la tarea revolucionaria, (re)posicionó a los varones, pero principalmente a las mujeres, quienes transgredieron y reubicaron -no sin tensiones y contradicciones- los estereotipos femeninos. Sin embargo, y luego de más de 40 años, ¿sigue reflejándose en los testimonios esta mentada igualdad?

\section{Militancia y Género en la Historiografía Reciente Argentina}

Como hemos mencionado, en las últimas décadas, las ciencias sociales en general -y la historia en particular- asistieron a un crecimiento significativo de las investigaciones sobre el campo de la denominada Historia Reciente. Este concepto remite al pasado cercano que, de alguna manera, 
no ha terminado de pasar y que por lo tanto interpela e involucra a los sujetos en la construcción de sus identidades individuales y colectivas.

En los últimos años los estudios sobre este campo de indagación han transformado paulatinamente la historiografía argentina, promoviendo el uso de nuevas perspectivas analíticas y metodologias de trabajo, favorecidas por el desarrollo de eventos académicos, formación de institutos y proyectos de investigación, y la publicación de revistas especializadas vinculadas al estudio de problemas históricos recientes. Estos debates se han enfocado principalmente en los años sesenta y setenta, reactualizando la agenda de las discusiones políticas e intelectuales de los distintos espacios, intra y extra académicos ${ }^{10}$. De esta manera, asistimos crecientemente a lecturas múltiples y heterogéneas de distintos problemas de investigación.

En el caso particular de la participación política de las mujeres en este periodo, los primeros trabajos -surgidos en la década de 1990-fueron de carácter testimonial/periodístico, en consonancia con el auge de este tipo de escrituras sobre la militancia setentista. Podemos mencionar aquí, entre otros, los testimonios vertidos en libros como Mujeres Guerrilleras de Marta Diana (1996), Pájaros sin luz de Noemí Ciollaro (1999) y obras testimoniales colectivas como Nosotras, presas politicas (2006) y Mujeres desde el Cordobazo hasta nuestros días, realizado por el Movimiento de Mujeres de Córdoba-Argentina (2006).

Como han señalado Viano y D'Antonio existen tres grandes núcleos temáticos que atraviesan las producciones que entrecruzan la perspectiva de género con la historia reciente en Argentina. Por un lado, aquellos que analizan las experiencias políticas y sociales marcadas por la militancia en organizaciones armadas y no armadas y dentro del feminismo hacia fines de los años sesenta y setenta. En ellos encontramos una problematización respecto de las experiencias de sociabilidad entre los sexos y las representaciones del mundo en relación al género y la política en este contexto histórico particular ${ }^{11}$. Un segundo núcleo problemático lo constituyen aquellos trabajos que abordan el periodo dictatorial (1976-1983), la represión a los distintos colectivos sociales (de los cuales las mujeres formaron parte), los delitos sexuales cometidos por las distintas fuerzas de seguridad y la emergencia de los organismos de Derechos Humanos desde una perspectiva sexo-genérica. Finalmente, encontramos un conjunto de trabajos que abordan los cambios socio-culturales y en la vida cotidiana acontecidos durante estas décadas, preguntándose por los modelos juveniles hegemónicos y "subversivos" y los cambios en los modelos de masculinidad y femineidad (Viano y D'Antonio, 2018: 25).

Queda un amplio abanico de problemas por abordar, un sinnúmero de preguntas que aún no han sido indagadas, como por ejemplo la exploración específica del mundo del trabajo con perspectiva de género, las experiencias de los sectores populares o avanzar en análisis que problematicen la masculinidad. Nos encontramos, además, con marcadas diferencias regionales, esto es, un mayor desarrollo de investigaciones en algunos lugares del país (generalmente grandes ciudades) y epocales, ya que cómo se mencionó una gran cantidad de trabajos se enfocaron en los años sesenta y setenta, dejando las etapas más actuales con una multiplicidad de temas/problemas pendientes de investigar. Aún así, es necesario señalar el avance sostenido de las pesquisas que abordan las experiencias de las mujeres y (y otros sujetos subalternizados) y la diversidad de tópicos trabajados, en un contexto complejo signado por profundas trasformaciones políticas, sociales e intergenéricas.

\section{Conclusión}

En el presente escrito hemos reflexionado sobre las potencialidades que el uso de fuentes orales tienen para la reconstrucción de la historia

\footnotetext{
10 La diversidad de perspectivas responde no solo a cuestiones de "campo disciplinar" sino también a (re)lecturas marcadas por los distintos procesos socio-políticos argentinos. Para un análisis de las distintas "etapas" de los relatos sobre los sesenta y setenta ver Pittaluga (2007).

11 Entre otras podemos mencionar Andújar, et al (2005; 2009 y 2010); Grammático (2011); Martínez (2008); Noguera (2019); Oberti (2015); Pasquali (2008); Sepúlveda (2015); Viano (2011).
} 
reciente y el estrecho vínculo existente con los estudios de género y memoria. Una pregunta central estructura nuestras indagaciones: ¿Narran los testimonios de las mujeres una "historia diferente"? La respuesta sería en parte afirmativa en la medida en que las narraciones sobre la historia reciente de nuestro país han sido trasmitidas y reconstruidas en base a concepciones masculinas (a lo que podriamos agregar blancas y heterosexuales), nociones reflejadas aún en el relato de las propias mujeres.

Aunque los resultados de la utilización de la historia oral en los estudios de género han sido muy variados hemos asistido en los últimos años a una explosión de investigaciones que analizan las relaciones genéricas, principalmente en las décadas de 1960 y 1970. De esta manera se ha producido paulatinamente una disputa en la (re) interpretación del pasado -aún dentro de los propios grupos con los cuales ellas y ellos se identifican- dando paso a escrituras de la historia que progresivamente van incorporando criticamente las experiencias no sólo de las mujeres sino también de otros sujetos y recuperando sus agencias.

Decimos que la inclusión de los testimonios de las mujeres sólo en parte superaría la subalternización/invisibilización de que son objeto/ sujeto las mujeres en la historia, si sólo se lo concibe como apéndice de las prácticas sociales de los varones o como una historia singular "de mujeres". En este sentido creemos necesario introducir operaciones críticas que deconstruyan los mecanismos de poder y dominación que reproducen las desigualdades entre las personas por razones de sexos, géneros y sexualidades, al mismo tiempo que no debemos ignorar las diferencias de clase y étnicas y al interior del propio género o del propio grupo con el cual el sujeto se encuentra identificado.

Quizás éstos sean los desafíos para quienes investigamos en estos campos disciplinares: promover reescrituras criticas de la Historia donde se formulen nuevas preguntas, se indague el por qué de la subordinación, se cuestionen las representaciones, las corporalidades, sin sustraerse, como sugiere Eric Hobsbawm (2004[1994]), del deber de universalismo al que está obligado el historiador, es decir, enmarcar en procesos históricos más amplios esa condición de subalternidad de la que son sujeto/objeto las mujeres -entre otros sujetos subalternizados/invisibilizados.

Finalmente, creemos que indagar la historia reciente de nuestro país desde una perspectiva de género aporta a comprender críticamente las formas y dinámicas de la construcción de la cultura socio-politica Argentina y contribuye a entenderla en relación al papel de las mujeres y a su participación en la vida pública. Esto último nos proporciona una herramienta más para mirar nuestro presente y quizás discernir lógicas excluyentes e incluyentes con respecto a la participación de las mujeres en la sociedad actual. El acto político de recordar, presente ciertamente en las escrituras de la Historia, debe interpelarnos no sólo para incorporar diversos puntos de vista en determinadas coyunturas históricas sino también, y fundamentalmente, para otorgarles agencia política a los sujetos que sobre ella han actuado.

\section{Bibliografía}

ACHA, Omar y HALPERÍN, Paula (Comp.). Cuerpos, Géneros, Identidades: estudios de Historia de género en Argentina. Buenos Aires: Ediciones del Signo, 2000

ACTIS, Munú; ALDINI, Cristina; GARDELLA, Liliana; LEWIN, Miriam; TOKAR, Elisa. Ese infierno: conversaciones de cinco mujeres sobrevivientes de la ESMA. Buenos Aires: Sudamericana, 2001.

ANDÚJAR, Andrea. Historia, género y memoria: las mujeres en los cortes de ruta en la Argentina. In: GRACIA, Gerardo Necochea; MASTRÁNGELO, Mariana; RODRÍGUEZ, Edna Ovalle; PENSADO, Patricia Leglise; RIBERA, Anna Carbó; VIANO, Cristina. Historia oral y militancia politica en México y en Argentina. Buenos Aires: Editorial El Colectivo y FFyL/UBA, pp. 95-119, 2008

ANDÚJAR, Andrea, D'ANTONIO, Débora; GRAMMÁTICO, Karin; ROSA, María (Comp.). Hilvanando historias: mujeres y politica en el pasado reciente latinoamericano. Ediciones Luxemburg, 2010. Disponible en: http://iiege. institutos.filo.uba.ar/otras_publicaciones.php. Acceso el: 10 de marzo de 2012

ANDÚJAR, Andrea; D'ANTONIO, Débora; DOMINNGUEZ, Nora; GRAMMÁTICO, Karin; GIL LOZANO, Fernanda; PITA, Valeria; RODRÍGUEZ, María Inés; VASSALLO, Alejandra (Comp.). Historia, género y política en los '70. Buenos Aires: Feminaria Editora, 2005 
ANDÚJAR, Andrea; D'ANTONIO, Débora; GIL LOZANO, Fernanda; GRAMMÁTICO, Karin; ROSA, Maria Laura (Comp.). De minifaldas, militancias y revoluciones: exploraciones sobre los ' 70 en la Argentina. Buenos Aires: Ediciones Luxemburg, 2009.

BARRANCOS, Dora. Mujeres en la sociedad argentina: una historia de cinco siglos. Buenos Aires: Sudamericana, 2007.

BEGUÁN, Viviane; KOZAMEH, Alicia; ECHARTE, Silvia. Nosotras, presas politicas. Buenos Aires: Nuestra América, 2006

BENHABIB, Seyla; CORNELL, Drucilla (Edit.). Teoria feminista y teoria crítica: ensayos sobre la política de género en las sociedades de capitalismo tardio. Valencia: Ediciones Alfons El Magnanim. Institució Valenciana D’Estudis I Investigació, 1990

BOCK, Giselle. La historia de las mujeres y la historia del género. Historia Social, n. 9. Valencia: Fundación Instituto de Historia Social, 1990, pp. 55-77.

BONDER, Gloria. Género y subjetividad: avatares de una relación no evidente. In: MONTECINO, Simone; KING, Alexandra, Obach. Género y Epistemologia: mujeres y disciplinas. Programa Interdisciplinario de Estudios de Género (PIEG), Universidad de Chile, 1990. Disponible en: http://Www.iin.oea.org/iin/cad/actualizacion/ pdf/Explotacion/genero_y_subjetividad_bonder.pdf. Acceso el 20 de junio de 2010.

BRUNER, Jerome. La Fábrica de Historias: derecho, literatura, vida. Buenos Aires: Fondo de Cultura Económica, 2003.

BUTLER, Judith. Cuerpos que importan: sobre los limites materiales y discursivos del "sexo". Buenos Aires: Paidós, 2002

CHARTIER, Roger. La historia hoy en dia: dudas, desafíos, propuestas. In: OLABARRI, Ignacio; CAPISTEGUI, Francisco. La "nueva" historia cultural: la influencia del postestructuralismo y el auge de la interdisciplinariedad. Madrid: Universidad Complutense, 1996.

CIOLLARO, Noemi. Pájaros sin luz: testimonios de mujeres de desaparecidos. Buenos Aires: Planeta, 1999.

D'ANTONIO, Débora. Transformaciones y experiencias carcelarias: prisión política y sistema penitenciario en la Argentina entre 1974 y 1983 . Tesis Doctoral en Historia. FFyL-UBA. Inédita, 2010

D'ANTONIO, Débora; VIANO, Cristina. A propósito de la historia reciente, la historia de las mujeres y los estudios de género: intersecciones y desafíos. In: ÁGUILA, G.; LUCIANI, L.; SEMINARA, L.; VIANO, C. (Comps.). La Historia reciente en argentina. Balances de una historiografía pionera en América Latina. Buenos Aires: Imago Mundi, pp. 19-38, 2018

DE CERTEAU, Michel. La escritura de la historia. Santa Fé: Universidad Iberoamericana, 1993[1978].

DE LAURETIS, Teresa. La tecnología del género. Mora: revista del Área Interdisciplinaria de Estudios de la Mujer-UBA. N. 2. Noviembre, 1996, pp. 6-34.
DIANA, Marta. Mujeres guerrilleras. Buenos Aires: Planeta, 1996

DUBY, Georges y PERROT, Michele. Historia de las mujeres. Madrid: Taurus, 1993.

FERNÁNDEZ, Ana. La mujer de la ilusión. Buenos Aires: Paidos, 1993.

FRANCO, Marina; LEVÍN, Florencia (Comp.). Historia reciente: perspectivas y desafíos de un campo en construcción. Buenos Aires: Paidós, 2007.

GRAMMÁTICO, Karin. Mujeres Montoneras: una historia de la Agrupación Evita. 1973-1974. Buenos Aires: Ediciones Luxemburg, 2011.

GRELE, Ronald. La historia y sus lenguajes en la entrevista de Historia Oral: ¿quien contesta a las preguntas de quien y por qué?. Historia y Fuente Oral No 5 . Barcelona: El paso de la historia, pp. 111-129, 1991.

HALBWACHS, Maurice. Memoria individual y memoria colectiva. Estudio, n. 16. Otoño de 2005. CEA/UNC, pp. 163-187, 2005

HARAWAY, Donna. Ciencia, cyborg y mujeres: la reinvención de la naturaleza. Barcelona: Cátedra, 1995[1991].

HOBSBAWM, Eric. La historia de la identidad no es suficiente. Sobre la Historia. Barcelona: Crítica, pp. 266-276, 2004 [1994].

JELIN, Elizabeth. Los trabajos de la memoria. Madrid: Siglo XXI, 2002.

LAU JAIVEN, Ana. La historia oral: una alternativa para estudiar a las mujeres. In: ARELLANO, Graciela de Garay (Coord.) La historia con micrófono: textos introductorios a la historia oral. México: Instituto Mora, pp. 90-101, 1994.

MARTÍNEZ, Paola. Género, politica y revolución en los años setenta: las mujeres del PRT-ERP. Buenos Aires: Imago Mundi, 2008

MILLET, Kate. Política Sexual. México: Aguilar, 1975 [1969].

MOVIMIENTO MUJERES DE CÓRDOBA. Mujeres desde el Cordobazo hasta nuestros días. Córdoba: Movimiento de Mujeres Córdoba, 2006

NOFAL, Rossana. Testimonios de la militancia: Los cruces del género. Mujeres guerrilleras (1996) de Marta Diana. Tucumán: Instituto Interdisciplinario de Estudios Latinoamericanos. Universidad Nacional de Tucumán, 2004

NOGUERA, Ana. Revoltosas y Revolucionarias: mujeres y militancia en la Córdoba setentista. Córdoba: Editorial UNC, 2019.

OBERTI, Alejandra. Las revolucionarias: militancia, vida cotidiana y afectividad en los setenta. Buenos Aires: Edhasa, 2015

OBERTI, Alejandra y PITTALUGA, Roberto. Memorias en montaje: escrituras de la militancia y pensamientos sobre la historia. Buenos Aires: Cielo por Asalto, 2006.

OKIN, Susan. Desigualdad de género y diferencias culturales. In: CASTELLS, Carme (Comp.). Perspectivas feministas en teoría politica. Barcelona: Paidós, pp. 185206, 1996[1994]. 
PASQUALI, Laura. Mandatos y voluntades: aspectos de la militancia de mujeres en la guerrilla. Revista Temas de Mujeres, n. 4. Universidad Nacional de Tucumán, 2008. Disponible en: http://Www. filo.unt.edu.ar/rev/temas/ num4.htm. Pág. 50-76. Acceso el 5 de mayo de 2009

PATEMAN, Carol. Criticas feministas a la dicotomía público/privado. In: CASTELLS, Carme (Comp.). Perspectivas feministas en teoria politica. Barcelona: Paidós, pp. 2-23, 1996.

PITTALUGA, Roberto. Miradas sobre el pasado reciente argentino. Las escrituras en torno a la militancia setentista (1983-2005). In: FRANCO, Marina; LEVÍN, Florencia (Comp.). Historia reciente. Perspectivas y desafios de un campo en construcción. Buenos Aires: Paidós, pp. 125-152, 2007.

POLLAK, Michael. Memoria, olvido, silencio: la producción social de identidades frente a situaciones limite. Buenos Aires: Al Margen ediciones, 2006.

PORTELLI, Alessandro. Lo que hace diferente a la historia oral. In: SCHWARZSTEIN, Dora (Comp). La historia oral. Buenos Aires: Centro Editor de America Latina, pp. 36-52, 1991.

RAMOS ESCANDÓN, Carmen (Comp.). Género e Historia. México: Antología Universitaria, 1992.

RICOEUR, Paul. La memoria, la historia, el olvido. Buenos Aires: Fondo de Cultura Económica, 2008[2000].

SCOTT, Joan. Género e Historia. México: Fondo de Cultura Económica, 2011 [1999].

SEMINARA, Luciana; VIANO, Cristina. Las dos Verónicas y los múltiples senderos de la militancia: de las organizaciones revolucionarias de los años ' $70 \mathrm{al}$ feminismo. In: ANDÚJAR Andrea; D'ANTONIO, Débora; GIL LOZANO, Fernanda; GRAMMÁTICO, Karin; ROSA, Maria Laura (Comp.). De minifaldas, militancias y revoluciones: exploraciones sobre los ' 70 en la Argentina. Buenos Aires: Ediciones Luxemburg, pp. 69-86, 2009.

SEPÚLVEDA, Patricia. Mujeres insurrectas: condición femenina y militancia en los '70. Buenos Aires: Universidad Nacional de Quilmes, 2015. Disponible en: http:// unidaddepublicaciones.web.unq.edu.ar/wp-content/ uploads/sites/46/2016/04/Mujeres-insurrectas-e-book.pdf. Acceso el 25 de junio de 2017.

STANLEY, Jo. Incluir los sentimientos: darse a conocer a uno mismo a través del testimonio político personal. Taller $\mathrm{N}^{\circ}$ 18. Vol. 6, pp. 135-155, 2002.

THOMPSON, Paul. Historia oral y contemporaneidad. Anuario, n. 20. Escuela de Historia. UNR. 2003/2004. Rosario: Homo Sapiens.

TRAVERSO, Enzo. La historia como campo de batalla: interpretar las violencias del siglo XX. Buenos Aires: Fondo de Cultura Económica, 2012.

VIANO, Cristina. Pinceladas sobre las relaciones de género en la nueva izquierda peronista de los primeros años '70. Revista Temas de Mujeres, v. 7. n.7. Universidad Nacional de Tucumán, 2011. Disponible en: http://www. filo.unt.edu.ar/rev/temas/num7.htm. Acceso el 26 de septiembre de 2015
VICH, Victor; ZAVALA, Virginia. Oralidad y poder: herramientas metodológicas. Buenos Aires: Norma, 2004.

\section{Ana Laura Noguera}

Doctora en Historia por la Universidad Nacional de Córdoba, (UNC, Córdoba, Argentina), becaria posdoctoral del Consejo Nacional de Investigaciones Científicas y Técnicas (CONICET), investigadora y profesora del Centro de Estudios Avanzados-Facultad de Ciencias Sociales de la Universidad Nacional de Córdoba (CEA-FCS-UNC), en Córdoba, Argentina.

\section{Dirección}

\section{Ana Laura Noguera}

Universidad Nacional de Córdoba

Av. Vélez Sarsfield 153

Centro, 5000

Córdoba, Argentina 